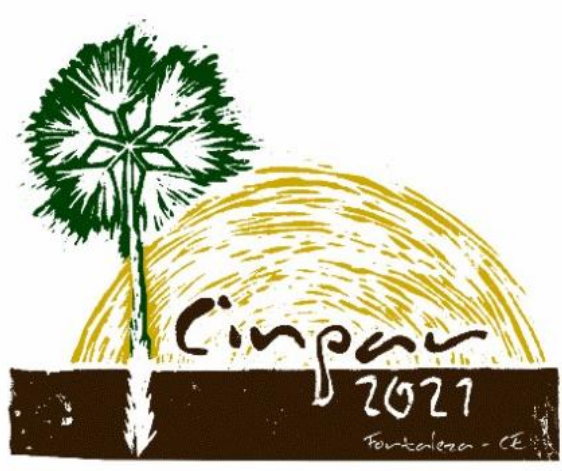

XVII Congresso Internacional sobre Patologia e

Reabilitação das Construções

XVII Congreso Internacional sobre Patología y Rehabilitación de las Construcciones

XVII International Conference on Pathology and Constructions Rehabilitation

FORTALEZA (Brasil), 3 a 5 de junho de 2021

https://doi.org/10.4322/CINPAR.2021.015

\title{
Análise comparativa de resistência mecânica e absorção capilar de argamassas produzidas por diferentes tipos de misturadores
}

\section{Comparative analysis of mechanical strength and absorption of mortars produced by different types of mixers}

\author{
Karina H. TANAKA ${ }^{1}$, Pedro H.V. KIRA², Paulo P. O. L. DYER ${ }^{3}$, Julia W. LENCIONI ${ }^{4}$, Carlos E. T. BALESTRA ${ }^{5}$, \\ Gustavo J. L. COPPIO 6 \\ ${ }^{1}$ Universidade do Vale do Paraiba, São José dos Campos, Brasil, karinaht_mia@hotmail.com \\ 2 Universidade do Vale do Paraíba, São José dos Campos, Brasil, pedrokira95@gmail.com \\ ${ }^{3}$ Instituto Tecnológico da Aeronáutica, São José dos Campos, Brasil, paulo_dyer@yahoo.com \\ ${ }^{4}$ Universidade do Vale do Paraíba, São José dos Campos, Brasil, jlencioni@univap.br \\ ${ }^{5}$ Universidade Tecnológica Federal do Paraná, Toledo, Brasil, carlosbalestra@utfpr.edu.br \\ ${ }^{6}$ Instituto Federal de São Paulo, Itapetininga, Brasil, gustavo.coppio@ifsp.edu.br
}

Resumo: Diferentes misturadores mecânicos são comumente utilizados em obra para a mistura de argamassas, apresentando cada um, diferentes particularidades operacionais. Neste ponto, os principais misturadores observados em obras correntes são a argamassadeira e a betoneira, sendo que, embora o último seja um equipamento destinado a mistura de concretos, onde há presença de agregados graúdos, este é um dos principais dispositivos mecânicos encontrados nas obras para a mistura de argamassas. Face ao exposto, o presente trabalho trata de uma análise comparativa de resistência mecânica à compressão e de absorção de água por capilaridade em argamassas produzidas a partir destes dois tipos de misturadores. Além disso, a análise de índice de vazios para dar suporte às análises de resistência e absorção também faz parte do escopo deste trabalho. Para tanto, argamassas com traço em volume 1: 1: 8 (Cimento: Cal: Areia) foram misturadas em ambos os misturadores e, posteriormente foram moldados corpos de prova prismáticos $(4 \times 4 \times 4 \mathrm{~cm})$ e cilindricos $(5 \times 10 \mathrm{~cm})$ para as análises de resistência e absorção capilar que permaneceram sob cura úmida por 28 dias. Os resultados demonstraram que as argamassas produzidas em argamassadeiras apresentam maior trabalhabilidade e resistência mecânica em relação às argamassas produzidas em betoneiras, possivelmente devido a maior homogeneidade obtida durante a mistura. Além disso, os resultados de absorção por capilaridade demonstraram que argamassas produzidas em argamassadeiras apresentam menores indices de absorção capilar de água e vazios, corroborando com as observações prescritas de maior resistência à compressão.

Palavras-chave: Argamassas, misturadores, resistência à compressão, absorção capilar.

Abstract: Different mechanical mixers are commonly used on site for mixing mortars, each presenting different operational particularities. At this point, the main mixers observed in construction are the mortar mixer and the concrete mixer, and, although the latter is an equipment intended for mixing concrete, where coarse aggregates are present, this is one of the main mechanical devices found in the constructions to mix the mortar. In view of the above considerations, the present work deals with a comparative analysis of mechanical resistance to compression and water absorption by capillarity in mortars produced from these two types of mixers. In addition, the void index analysis to support the resistance and absorption analyzes is 
also part of the scope of this work. For this, mortars with a trace in volume 1: 1: 8 (Cement: Lime: Sand) were mixed in the two mixers and subsequently molded prismatic $(4 \times 4 \times 4 \mathrm{~cm})$ and cylindrical $(5 \times 10 \mathrm{~cm})$ specimens, for analysis of resistance and capillary absorption that remained under moist cure for 28 days. The results showed that mortars produced in mortar mixers have greater workability and mechanical resistance in relation to mortars produced in concrete mixers, possibly due to the greater homogeneity obtained during mixing. Furthermore, the results of capillarity absorption showed that mortars produced in mortar mixers have lower indices of capillary water absorption and voids, corroborating the prescribed observations of greater compressive strength.

Keywords: Mortars, mixers, compressive strength, Capillary absorption.

\section{Introdução}

A mistura homogênea de agregado(s) miúdo(s), aglomerante(s) inorgânico(s) e água com propriedades de aderência e endurecimento, sendo aplicadas para assentamento de unidades de alvenaria ou peças cerâmicas, ou ainda na excução de camadas de revestimento definem o que são argamassas (ABNT, 2005). Tendo em vista a produtividadem, as argamassas são, em geral, misturadas de maneira mecânica nos canteiros de obra. Dois tipos de misturadores são comumentemente observados em obra para a realização da mistura da argamassa: as betoneiras (misturadores de eixo inclinado) e as argamassadeiras (misturadores de eixo horizontal).

Segundo dados apresentados por Romano et al (2009), nas argamassadeiras (Figura 1a), ou misturadores de eixo horizontal, as camadas mais externas de argamassa são empurradas para o interior da massa, impondo intenso cisalhamento ao material e facilitando a entrada de ar. Já nas betoneiras (Figura 1b), ou misturadores de eixo inclinado, a mistura ocorre após sucessivas quedas de parte da argamassa sobre o restante do material encontrado na parte inferior do equipamento. No casod as betoneiras, a inclinação interfere diretamente na eficiência da mistura e incorporação de ar, onde quanto mais horizontal for a posição do misturador, menor será a eficiência da mistura e a incorporação de ar.

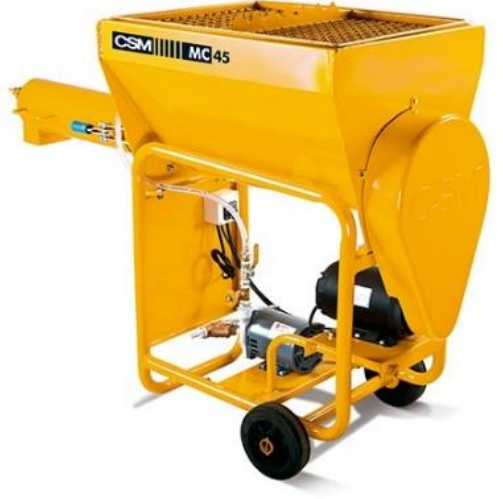

(a)

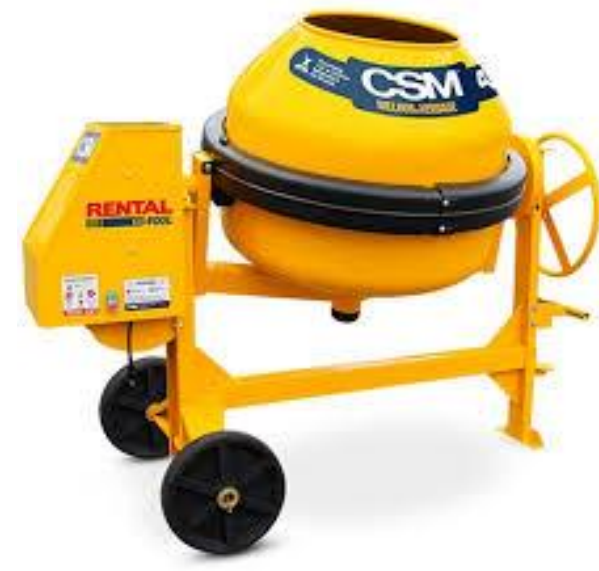

(b)

Figura 1 - Tipos de misturadores de argamassa verificados em obra: (a) argamassadeira (CSM, 2020b);

(b) betoneira (CSM, 2020a)

Conforme discutido por Craeye et al (2019), o procedimemento de mistura, o traço e o tipo de misturador podem afetar as propriedades da argamassa, tanto no estado fresco (consistência), quanto no estado endurecido, em diferentes idades (resistência à compressão e à flexão, porosidade). A resistência à compressão e a incorporação de ar são significativamente afetadas pelo tipo de misturador empregado.

Mediante o exposto, impera a necessidade de conhecer quais as variações nas propriedades das argamassas executadas através de diferentes tipos de misturador. Desta maneira, o presente trabalho apresenta um estudo comparativo entre argamassas de mesmo traço misturadas mecanicamente através de misturadores 
de eixo inclinado e vertical, abordando os efeitos da mistura sobre suas propriedades no que tange a resistência à compressão e a absorção de água por capilaridade.

\section{Materiais e Métodos}

A mistura das argamassas e a moldagem dos corpos de prova empregados neste trabalho foram realizadas em ambiente de obra, tendo sido utilizados os materiais e equipamentos empregados pela obra em questão. Foram utilizados os seguintes materiais: (1) cimento CPII-F 32, (2) cal hidratada CH-III, (3) areia natural média, proveniente de rio. $\mathrm{O}$ traço de argamassa em volume utilizado nesta pesquisa em cada misturador foi $1: 1$ : 8 (Cimento : Cal : Areia). Este traço foi adotado por solicitação do engenheiro responsável pela obra. Neste ponto, foram utilizadas recipientes de 18 litros para a determinação da proporção dos materiais.

De posse dos materiais, estes foram colocados nos respectivos misturadores, sendo que em primeiro lugar, foram colocadas metade da areia e da água e todo o cimento e toda a cal. Estes materiais foram misturados até se obter certa homogeneidade (cerca de 1 minuto) e, posteriormente, foi adicioado o restante da areia e da água, a partir das quais a mistura foi realizada por mais 3 minutos. A Figura 2 apresenta os misturadores utilizados.

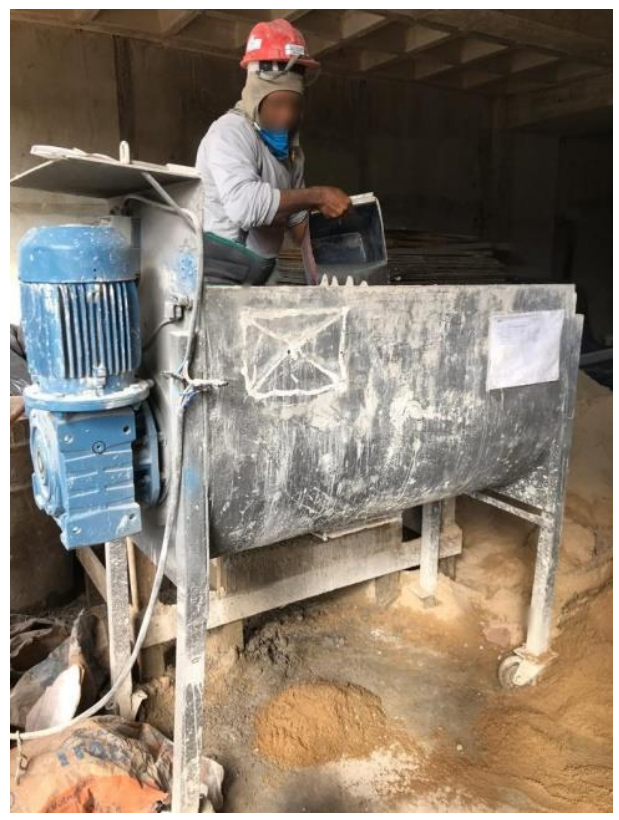

(a)

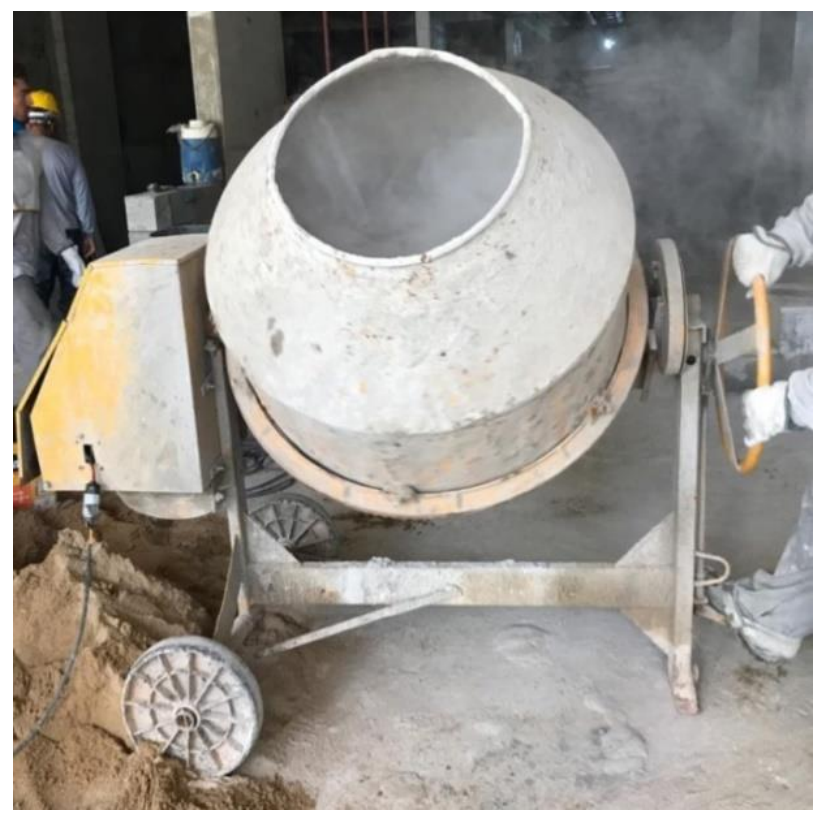

(b)

Figura 2 - Misturadores: (a) argamassadeira (marca Ekipabem, modelo E-600; 3500 rpm, 7,5 cv);

(b) betoneira (marca CSM, modelo SUPER-400, $26 \mathrm{rpm}, 2 \mathrm{cv}$ ).

Após a mistura, foram moldados 6 corpos de prova cúbicos de $40 \times 40 \times 40 \mathrm{~mm}$ por misturador para a execução de ensaios de compressão, e 6 corpos de prova cilíndricos de $50 \times 100 \mathrm{~mm}$ (diâmetro $\times$ comprimento) por misturador para a execução de ensaios de absorção de água por capilaridade e índice de vazios, conforme mostrados na Figura 3. Os corpos de prova cúbicos foram moldados com base no Anexo $D$ da norma NBR 15961-2 (ABNT, 2011), que prevê o uso dos corpos de prova cúbicos como uma alternativa para a moldagem dos corpos de prova em ambiente de obra, como o ocorrido neste trabalho. Os corpos de prova cilíndricos foram moldados com base na NBR 7215 (ABNT, 2019). Os corpos de prova cúbicos foram desformados após 48 h e os cilíndricos após 24 h, permanecendo sob cura úmida por imersão até a realização dos respectivos ensaios em ambiente controlado (laboratório comercial). 


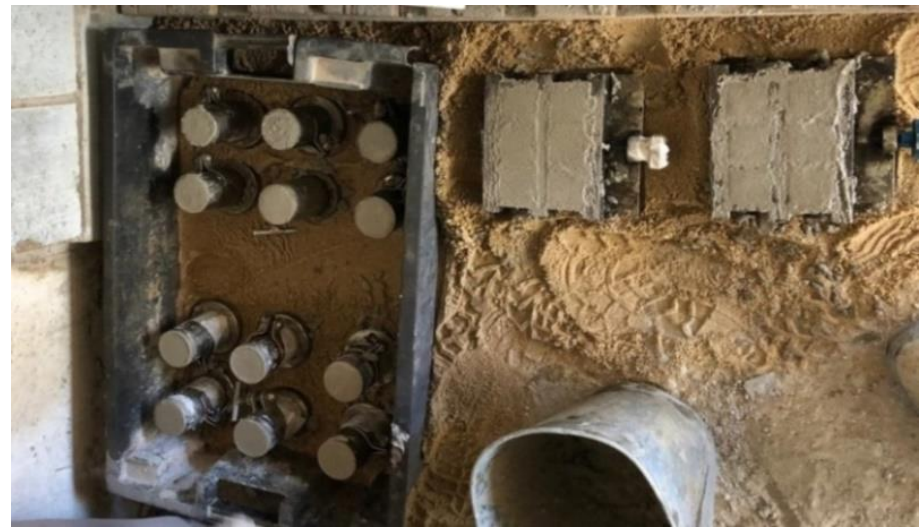

Figura 3 - Corpos de prova de argamassa para a realização de ensaios

Após o período de cura, os corpos de prova prismáticos foram ensaiados à compressão e os corpos de prova cilindricos foram submetidos ao ensaio de absorção de água por capilaridade. No primeiro ensaio, realizado em conformidade com a NBR 15961-2 (ABNT, 2011), os corpos de prova foram submetidos à uma carga de compressão uniaxial igual a $500 \pm 50 \mathrm{~N} / \mathrm{s}$ até sua ruptura aos 7 e aos 28 dias, sendo o gradiente entre a carga máxima e a área comprimida o valor correspondente à resistência à compressão da argamassa.

Para o ensaio de absorção por capilaridade, conduzido conforme a NBR 9779 (ABNT, 2012), 3 corpos de prova cilíndricos de cada misturador foram secos em estufa, à uma temperatura de $(105 \pm 5){ }^{\circ} \mathrm{C}$, para determinação da sua massa ao ar. Em seguida, os corpos de prova foram submetidos ao resfriamento $\left(23 \pm 2^{\circ} \mathrm{C}\right)$, em um dessecador, para determinação da massa seca. Posteriormente, foram mantidos em um ambiente com temperatura constante de $23 \pm 2{ }^{\circ} \mathrm{C}$ e colocados em um recipiente preenchido com água até o nível de $5 \pm 1$ $\mathrm{mm}$ acima da sua face inferior, apoiados sobre suportes (Figura 4). Foram determinadas as massas dos corpos de prova após $3 \mathrm{~h}, 6 \mathrm{~h}, 24 \mathrm{~h}, 48 \mathrm{~h}$ e $72 \mathrm{~h}$, contadas a partir do momento em que o material entrou em contato com a água do recipiente. Antes da pesagem, os corpos de prova tiveram o excesso de água da sua superfície removido com um pano úmido e após serem pesados retornaram imediatamente ao recipiente com água.

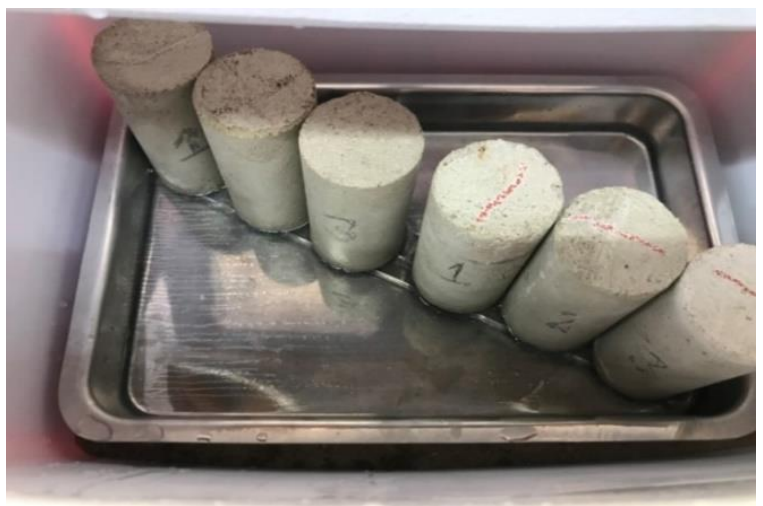

Figura 4 - Ensaio de absorção de água por capilaridade

Após serem realizadas todas as pesagens, a absorção de água por capilaridade foi calculada pela Equação 1.

$$
\mathrm{C}=\frac{m s a t-m s}{S}
$$

Onde: C é a absorção de água por capilaridade $\left(\mathrm{g} / \mathrm{cm}^{2}\right)$; msat é a massa saturada do corpo de prova (g); ms é a massa do corpo de prova seco (g); S é a área da secão tranversal do corpo de prova $\left(\mathrm{cm}^{2}\right)$.

A determinação do índice de vazios foi realizada em conformidade com a NBR 9778 (ABNT, 2005), empregando 3 corpos de prova cilíndricos de cada misturador. Primeiramente, as amostras foram postas em uma estufa, a temperatura de $105 \pm 5{ }^{\circ} \mathrm{C}$, sendo determinada a massa dos corpos de prova após a 
permanência na estufa por $24 \mathrm{~h}, 48 \mathrm{~h}$ e $72 \mathrm{~h}$. Os corpos de prova foram posteriormente resfriados em um ambiente com temperatura de $23 \pm 2{ }^{\circ} \mathrm{C}$, sendo em seguida determinada novamente a sua massa. $\mathrm{Na}$ sequência, as amostras foram imersas em água, à temperatura de $23 \pm 2{ }^{\circ} \mathrm{C}$, por $72 \mathrm{~h}$.

Feita a etapa de saturação, os corpos de prova foram colocados em um recipiente com água que foi progressivamente levado à ebulição por 5 h (Figura 5a). A água foi então resfriada, pela perda natural do calor, até atingir a temperatura de $(23 \pm 2)^{\circ} \mathrm{C}$. Posteriormente, os corpos de prova foram retirados da água e foi realizada a sua pesagem com uma balança hidrostática (Figura $5 b$ ), determinando a massa do material imerso. Depois, os corpos de prova foram enxutos com um pano úmido e pesados, determinando a sua massa no estado saturado.

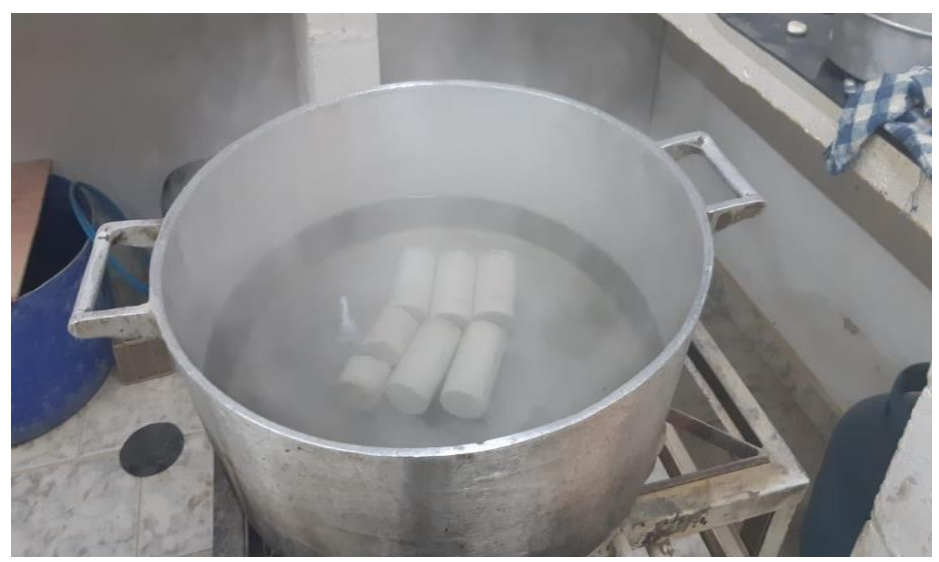

(a)

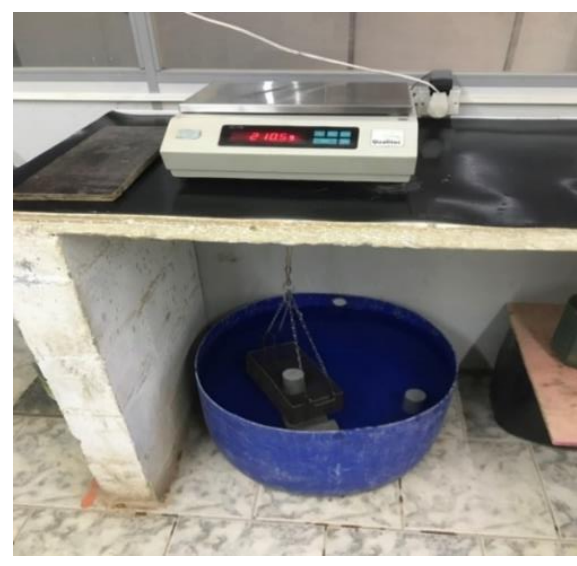

(b)

Figura 5 - Ensaio para determinação do indice de vazios: (a) procedimento de fervura dos corpos de prova; (b) determinação da massa submersa em balança hidrostática

O índice de vazios foi obtido com a aplicação da Equação 2.

$$
\mathrm{IV}=\frac{m s a t-m s}{m s a t-m i} \times 100
$$

Onde: Iv é o índice de vazios (\%); msat é a massa da amostra saturada em água após imersão e fervura (g); ms é a massa da amostra seca em estufa; mi é a massa da amostra saturada imersa em água após fervura (obtida pela pesagem hidrostática).

\section{Resultados e Discussões}

A Figura 6 apresenta os resultados médios de resistência à compressão das argamassas misturadas através dos diferentes tipos de misturadores, ao passo que a Figura 7 apresenta os resultados de absorção de água por capilaridade. Os índices de vazios obtidos foram $24,19 \%$ e $25,75 \%$ para as misturas realizadas em argamassadeira e em betoneira, respectivamente. 


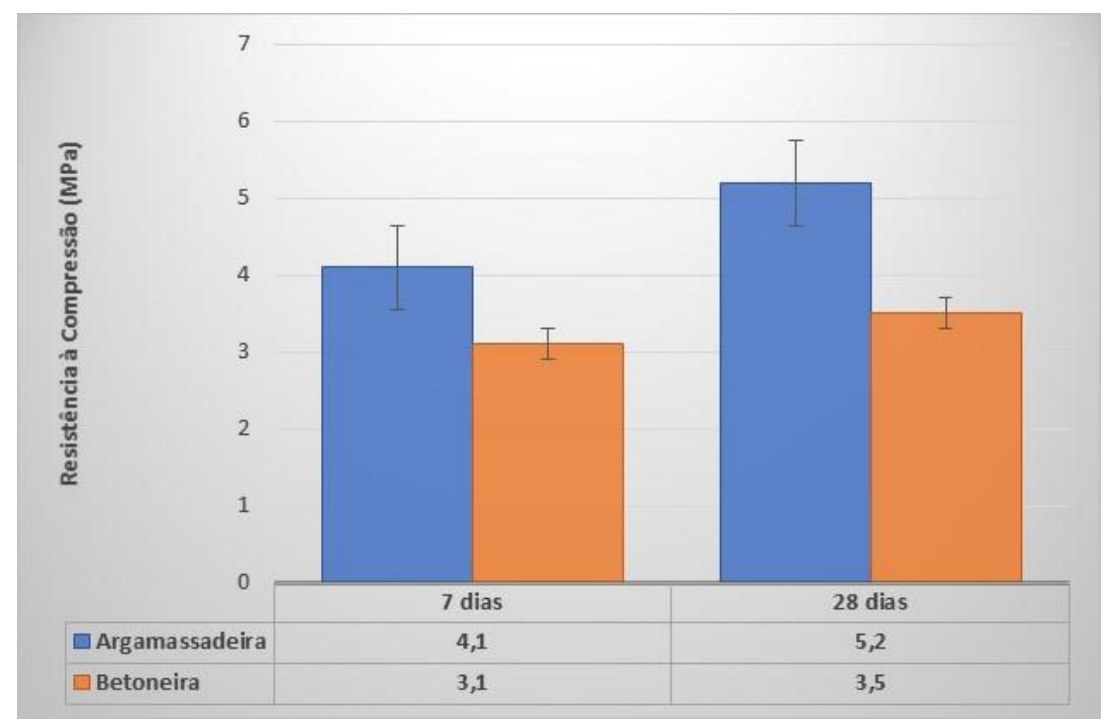

Figura 6 - Resistência à compressão das argamassas segundo diferentes misturadores

Apesar dos baixos valores obtidos para a resistência à compressão, analisando os valores médios, verifica-se que, aos 28 dias de idade, a argamassa preparada na argamassadeira atingiu uma resistência mecânica cerca de $48,6 \%$ superior à resistência mecânica atingida pela argamassa preparada na betoneira. Esse acréscimo de resistência demonstra uma melhor eficiência da argamassadeira, obtendo-se uma mistura mais homogênea e, por consequência, com maior resistência mecânica. Tal fato corrobora com o menor indice de vazios observado nas argamassas misturadas em argamassadeiras, demonstrando que por apresentar menor porosidade, maior foi a resistência à compressão obtida.

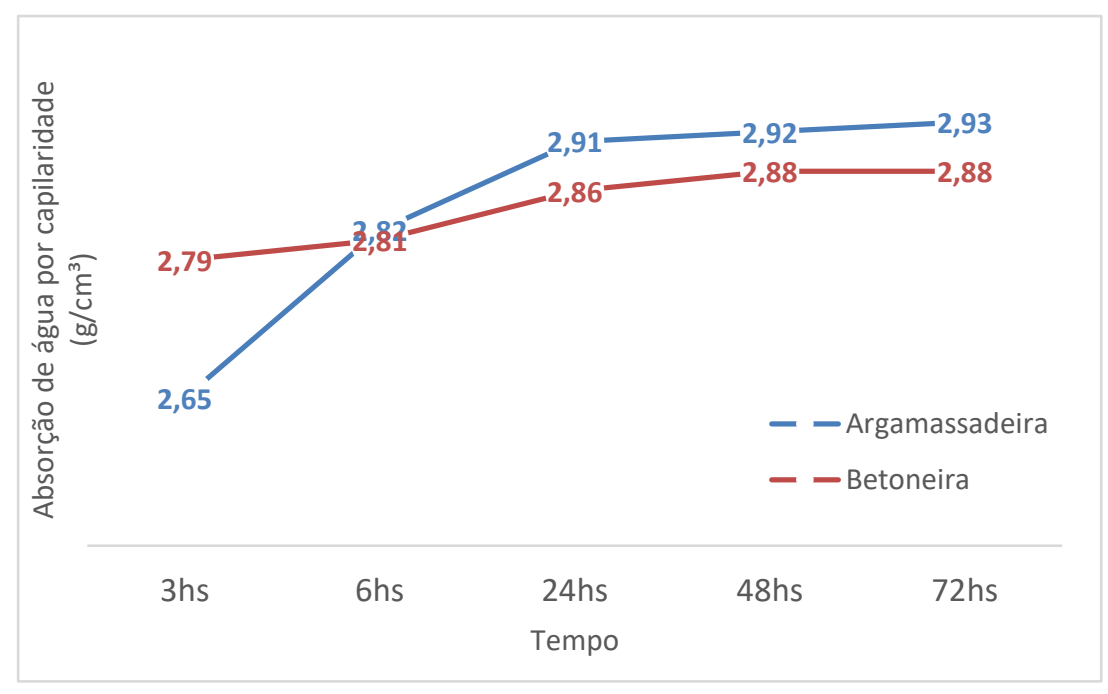

Figura 7 - Absorção de água por capilaridade

Com relação à absorção de água por capilaridade, observa-se que argamassas misturadas em betoneira apresentaram maior absorção de água por capilaridade na primeira medida horária (3h), e que embora observa-se que o comportamento tenha se invertido a partir de $6 \mathrm{~h}$, as diferenças entre ambas argamassas misturadas em misturadores diferentes se mantiveram pequenas. Isto, aliado aos índices de vazios obtidos, leva a afirmar que as argamassas misturadas em betoneira apresentam maior quantidade de poros capilares interconectados. Consequentemente, considerando que absorção de água é um processo no qual a água carrega para o interior das estruturas uma diversidade de espécies químicas capaz de interagir tanto com os materiais cimetícios quanto com as armaduras, recomenda-se atenção quanto ao uso de argamassas 
misturadas em betoneiras para aplicação em revestimentos e fachadas que estejam susceptíveis ao contato com a umidade.

\section{Conclusões}

Este trabalho apresenta uma análise comparativa da resistência à compressão e da absorção de água de argamassas com traço $1: 1: 8$ (Cimento : Cal : Areia), produzidas empregado distintos misturadores mecânicos - argamassadeira e betoneira - e sob as condições de um canteiro de obra. As principais conclusões obtidas para este trabalho são:

- A resistência à compressão uniaxial da argamassa misturada em argamassadeira foi quase $50 \%$ maior do que a resistência à compressão da argamassa misturada em betoneira, aos 28 dias. Os resultados referentes ao índice de vazios corroboram para justificar esse comportamento.

- A absorção de água da argamassa executada em betoneira é maior nas primeiras $3 h$, tendo em vista sua porosidade capilar. Desta maneira, cuidados devem ser levados em consideração quando essa argamassa for utilizado em obras que venham a ter contato com a umidade.

\section{Agradecimentos}

Os autores agradecem ao Centro de Desenvolvimento Tecnológico da Construção Civil (CDTCC) pelo apoio técnico-financeiro dado ao desenvolvimento deste trabalho, à Universidade do Vale do Paraíba (UNIVAP), à Universidade Tecnológica Federal do Paraná - Toledo (UTFPR-TD), ao Instituto Federal de São Paulo Piratininga (IFSP - Piratininga).

\section{Referências}

ASSOCIAÇÃO BRASILEIRA DE NORMAS TÉCNICAS. NBR 13281: Argamassa para assentamento e revestimento de paredes e tetos - Requisitos. Rio de Janeiro, 7p. 2005.

ASSOCIAÇÃO BRASILEIRA DE NORMAS TÉCNICAS. NBR 15961-2: Alvenaria estrutural - Blocos de concreto Parte 2: Execução e controle de obras. Rio de Janeiro, 35p. 2011.

ASSOCIAÇÃO BRASILEIRA DE NORMAS TÉCNICAS. NBR 7215: Cimento Portland - Determinação da resistência à compressão de corpos de prova cilíndricos. Rio de Janeiro, 12p. 2019.

ASSOCIAÇÃO BRASILEIRA DE NORMAS TÉCNICAS. NBR 9778: Argamassa e concreto endurecidos Determinação da absorção de água, índice de vazios e massa específica. Rio de Janeiro, 4p. 2009.

ASSOCIAÇÃO BRASILEIRA DE NORMAS TÉCNICAS. NBR 9779: Argamassa e concreto endurecidos Determinação da absorção de água por capilaridade. Rio de Janeiro, 3p. 2012.

CRAEYE et al. (2019). Comparative study on the effect of mixer type on properties of self-compacting mortar. Rheology and Processing of Construction Materials. 283 - 293.

CSM. Argamassadeira MC 45. Disponível em: https://www.csm.ind.br/maquinas/services/argamassadeiramc-45/. Acesso em: 4 Dez. 2020a.

CSM. Nova Betoneira Rental 400 litros. Disponivel em: https://www.csm.ind.br/maquinas/nova-betoneirarental-400-litros/. Acesso em 4 Dez. 2020b.

ROMANO et al. (2009). Impacto do tipo de misturador e do tempo de mistura nas propriedades de argamassas industrializadas. Ambiente Construído. 9 (4), 109-118. 